\title{
A VALIDATION OF THE EFFECTIVENESS OF INNER DEPENDENCE IN AN ANP MODEL
}

\author{
Rozann Saaty \\ Creative Decisions Foundation \\ Pittsburgh, PA 15213 \\ Email: rozann@creativedecisions.net
}

\begin{abstract}
Validation is important when dealing with decision models such as those using the Analytic Hierarchy Process (AHP) and the Analytic Network Process (ANP). The only way to know whether the results are right that we get with any decision theory is to validate that they match real world outcomes. In this paper we start with an AHP car-buying model, convert it to an ANP model by removing the goal and adding feedback from the alternatives to the criteria, and at the third step add inner dependence among the criteria. We show here that at each step the results are nearer what we know occurs in the real world. Most of us, when buying a car, start out with the prudent expectation that we will purchase a serviceable inexpensive vehicle. This is top-down hierarchical thinking with price looming large in our considerations. After visiting the showroom, full of glossy late-model cars, however, we often do not buy the least expensive car. Feedback has occurred. Seeing the actual cars causes us to revise our priorities and price begins to seem less important. The final step is realizing that it is unavoidable; to get more prestige and comfort we have to pay a higher price; prestige and comfort take on higher priority as the priority of price diminishes; this is the outcome of the final step in which inner dependence among the criteria was included in the model. This is a validation exercise that shows using feedback and dependence in an ANP model can get us closer to reality.
\end{abstract}

Keywords: AHP, ANP, Validation

\section{Introduction}

In this paper we will illustrate that moving from AHP to ANP decision making allows one to more closely model the real world. We will first structure a car-buying decision as a hierarchical model with three levels: goal, criteria and alternatives; then turn it into an ANP model with feedback by removing the goal and creating links from the alternatives to the criteria; and finally change it further into an ANP model with inner dependence among the criteria.

These are the 4 criteria in the model: Prestige, Price, Miles per Gallon and Comfort, and the three cars are the Acura, the Camry and the Honda Civic, as shown in Figure 1. The cars have a mix of properties: price, that ranges from expensive to inexpensive, various levels of perceived prestige and comfort, and MPG. The data for the criteria are different in how we interpret them; MPG and price are both tangibles, but higher price is negatively valued, and higher MPG is positively valued; prestige and comfort are intangibles that are personal and subjective and can only be interpreted by the decision maker in light of their own understanding, morals and so on. Thus the data involved is very different for the four criteria, and it must be interpreted. The way that interpretation gets included in the model is through the judgments of the decision maker. In the case of MPG more is better, in the case of price, more is worse. Interpreting 
the data is subjective, even when it is expressed as numbers, like price. A person who is financially welloff may prefer a car that costs more, just because it costs more. For this exercise we suppose the decision maker is an average cost-conscious American family.

The Acura TL is the expensive prestigious car, the Toyota Camry is mid-priced and the Honda Civic is the least expensive and has some status as it is perceived as the "green" environmentally correct choice.

\section{The Cars}

- Acura TL

- Cost $\$ 30,000-\$ 35,000$

- Miles per Gallon 20/29 (City/Hwy)

- Prestige is very good

- Comfort is excellent

- Toyoto Camry

- Cost $\$ 22,000$ - $\$ 28,000$

- Miles per gallon 22/30 (City/Hwy)

- Prestige is good

- Comfort is good

- Honda Civic

- Cost $\$ 16,000$ - $\$ 20,000$

- Miles per gallon 29/38 (City/Hwy)

- Prestige is good - "green" car

- Comfort is medium to low

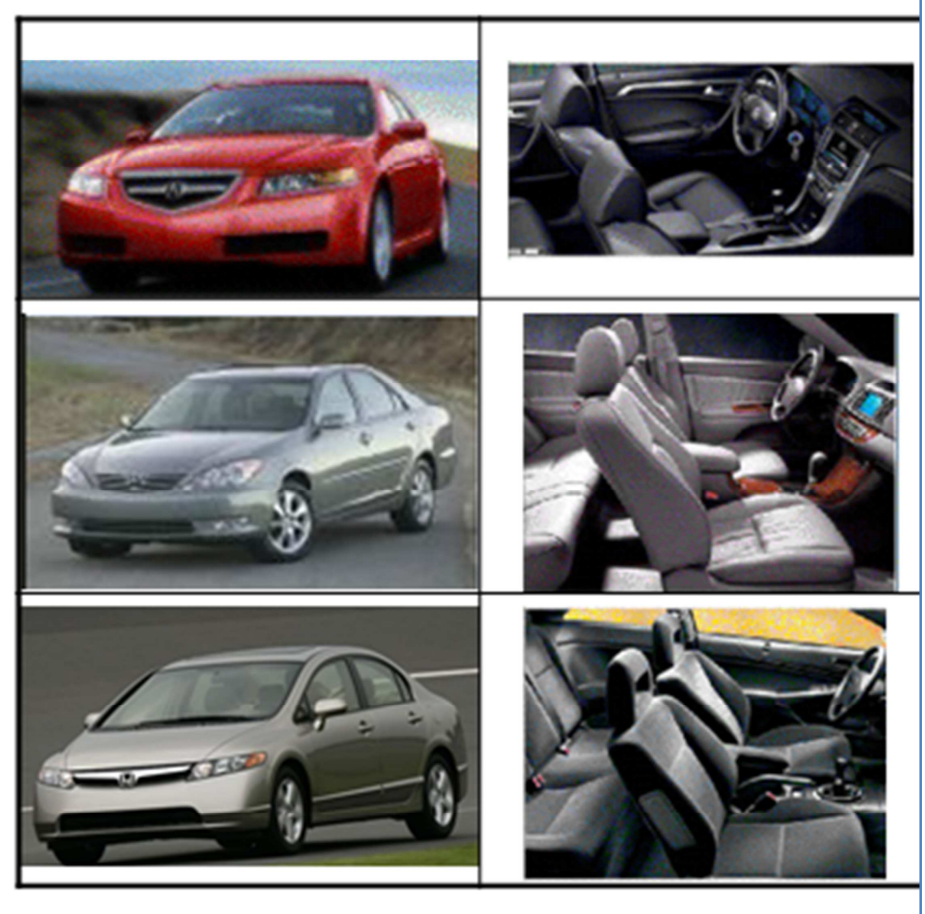

Figure 1 Choose the best of these three cars

\section{Hierarchical Model to Choose Best Car}

The decision model is structured as a three-level hierarchy with the goal at the top, the criteria in the second level and the alternatives at the bottom as shown in Figure 2. The priorities are determined from the top down in this model with the criteria being pairwise compared with respect to the goal, and the cars pairwise compared with respect to the four criteria. There are 5 pairwise comparison matrices altogether and the priority vectors are obtained by finding the eigenvalue of the pairwise comparison matrix.

Usually the solution for a hierarchy, the priorities of the alternatives, is obtained by weighting and adding priority vectors throughout throughout the model, but the solution can also be obtained using the square "supermatrix" comprised of the priority vectors located vertically in the column of the parent node of the comparisons from which it was obtained. For example, in Table 1 the priority vector obtained by pairwise comparing the cars with respect to Prestige is the vertical vector at the bottom in the column of 
the Prestige node. The solution of the supermatrix is obtained by raising it to powers until it converges to a steady state, the limit supermatrix. In a hierarchy, the columns are stochastic; that is, all the columns in the supermatrix sum to one and this is necessary for the supermatrix to converge. The power at which it converges is one less than the number of levels in the hierarchy.

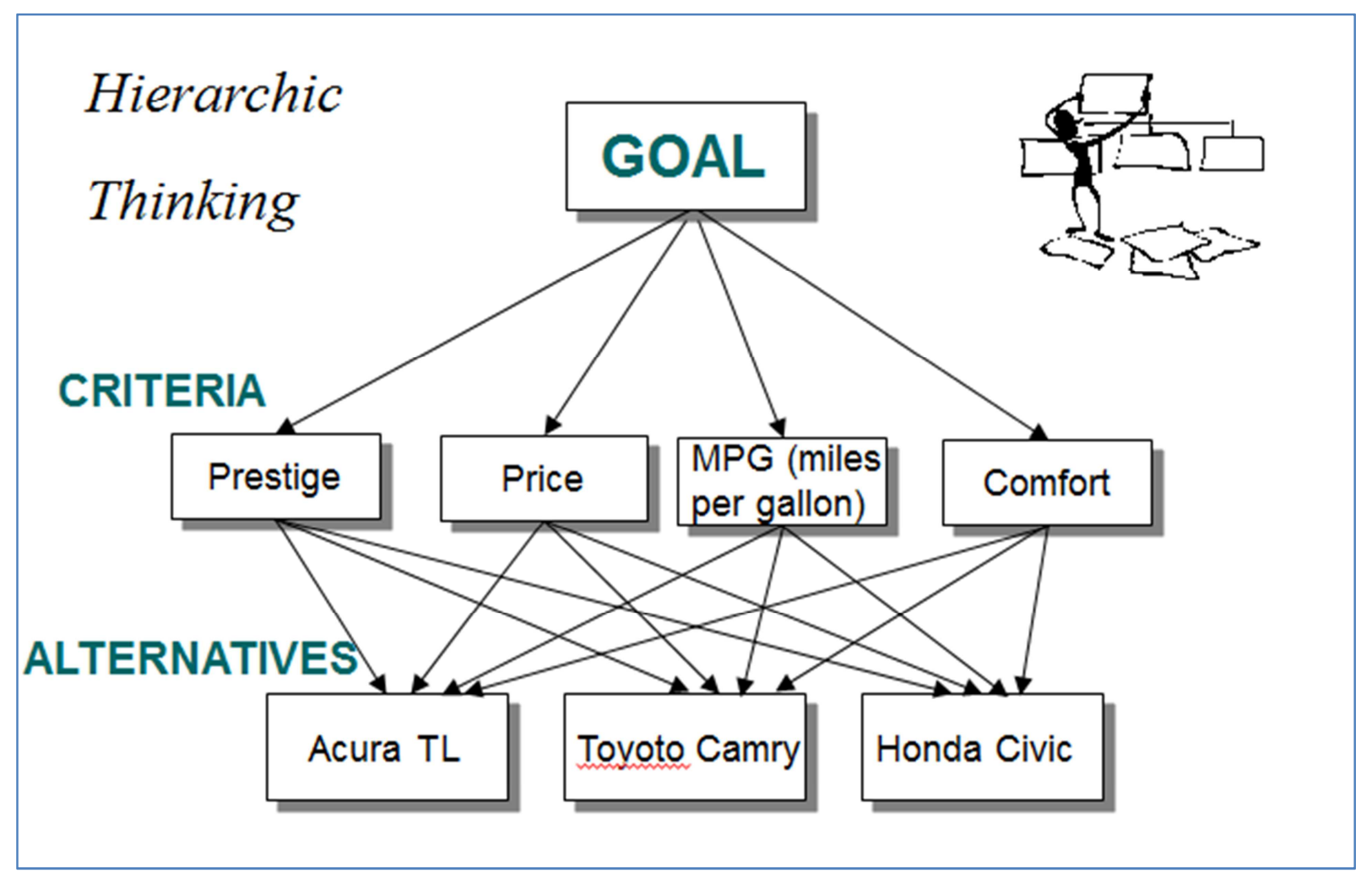

Figure 2 Three-level Hierarchical Model for choosing the Best Car

The supermatrix of a hierarchy requires special treatment to converge. The identity matrix must be inserted in the (alternatives, alternatives) component, shown in Table 1, as Saaty suggests in his books on the ANP (Saaty, 2013). This is equivalent to inserting self-loops on the alternatives and it is necessary for the supermatrix to converge. Without self-loops the elements in the matrix eventually all become zero. The supermatrix in Table 1 converges quickly to a steady state at the second power, shown in Table 2 . Raising it to higher powers brings no change in the matrix.

An interesting fact about hierarchies is that the power at which the supermatrix converges is $n-1$, where $n$ is the number of levels in the hierarchy. In most of the matrices in this paper, we display 6 significant figures, too many for reporting results from a decision model, just to allow readers studying this example, and raising matrices to powers in the process, to replicate our numbers. The models used here were created using the SuperDecisions software (Adams, et al., 2013) and are part of the sample tutorial models. The supermatrix data can be exported as .txt files that can be opened using Excel. This software is available free to educators and researchers at www.superdecisions.com.

\section{Table 1 Supermatrix of Hierarchical Model}




\begin{tabular}{ll|c|ccccc|ccc}
\hline \hline & \multicolumn{3}{c}{ 1Goal* $^{*}$} & \multicolumn{3}{c}{ 2Criteria } & \multicolumn{3}{c}{ 3Alternatives } \\
\hline \hline & & $\begin{array}{l}\text { Goal } \\
\text { Node }\end{array}$ & 1Prestige & 2Price & 3MPG & $\begin{array}{l}\text { 4Comfo } \\
\text { rt }\end{array}$ & $\begin{array}{l}\text { 1Acur } \\
\text { a }\end{array}$ & $\begin{array}{l}\text { 2Toyot } \\
\text { a }\end{array}$ & $\begin{array}{l}\text { 3Hond } \\
\text { a }\end{array}$ \\
\hline $\begin{array}{l}\text { 1Goal } \\
\text { 2Criteri } \\
\text { a }\end{array}$ & Goal & 0 & 0 & 0 & 0 & 0 & 0 & 0 & 0 \\
& 1Prestige & 0.0987 & 0 & 0 & 0 & 0 & 0 & 0 & 0 \\
& 2Price & 0.4250 & 0 & 0 & 0 & 0 & 0 & 0 & 0 \\
& 3MPG & 0.1686 & 0 & 0 & 0 & 0 & 0 & 0 & 0 \\
3Altern & 4Comfort & 0.3078 & 0 & 0 & 0 & 0 & 0 & 0 & 0 \\
-atives & 1Acura & 0 & 0.7071 & 0.0633 & 0.1818 & 0.7049 & 1 & 0 & 0 \\
& 2Toyota & 0 & 0.0702 & 0.1939 & 0.2727 & 0.2109 & 0 & 1 & 0 \\
& 3Honda & 0 & 0.2227 & 0.7429 & 0.5455 & 0.0841 & 0 & 0 & 1 \\
\hline
\end{tabular}

*Nodes and clusters are numbered because the SuperDecisions software used for the computations relies on alphabetical order, so numbering them allows us to control their order.

For a three-level hierarchy the limit supermatrix is reached at the second power, shown in Table 2. Notice that it gives the overall priorities of the alternatives in the Goal column and the priorities of the cars with respect to the criteria in the criteria columns. An interesting fact is that the supermatrix for a hierarchy reaches the steady state when the power is equal to the number of levels beneath the Goal.

Table 2 Limit Supermatrix of Hierarchical Model

\begin{tabular}{|c|c|c|c|c|c|c|c|c|c|}
\hline & & \multicolumn{2}{|l|}{ 1Goal } & \multicolumn{3}{|c|}{ 2Criteria } & \multicolumn{3}{|c|}{ 3Alternatives } \\
\hline & & $\begin{array}{l}\text { Goal } \\
\text { Node }\end{array}$ & $\begin{array}{l}\text { 1Prestig } \\
\text { e }\end{array}$ & 2Price & $3 \mathrm{MPG}$ & $\begin{array}{l}\text { 4Comfo } \\
\mathrm{rt}\end{array}$ & $\begin{array}{l}\text { 1Acur } \\
\mathrm{a}\end{array}$ & $\begin{array}{l}\text { 2Toyot } \\
\text { a }\end{array}$ & $\begin{array}{l}\text { 3Hond } \\
\text { a }\end{array}$ \\
\hline \multirow{4}{*}{$\begin{array}{l}\text { 1Goal } \\
\text { 2Criteria }\end{array}$} & Goal & & & & & & & & \\
\hline & Node & 0 & 0 & 0 & 0 & 0 & 0 & 0 & 0 \\
\hline & 1Prestige & 0 & 0 & 0 & 0 & 0 & 0 & 0 & 0 \\
\hline & 2Price & 0 & 0 & 0 & 0 & 0 & 0 & 0 & 0 \\
\hline \multirow{6}{*}{$\begin{array}{l}\text { 3Alternativ } \\
\text { es }\end{array}$} & $3 \mathrm{MPG}$ & 0 & 0 & 0 & 0 & 0 & 0 & 0 & 0 \\
\hline & 4Comfort & 0 & 0 & 0 & 0 & 0 & 0 & 0 & 0 \\
\hline & & & & 0.063 & 0.181 & & & & \\
\hline & 1Acura & 0.3443 & 0.7071 & $\begin{array}{c}3 \\
0.193\end{array}$ & $\begin{array}{c}8 \\
0.272\end{array}$ & 0.7049 & 1 & 0 & 0 \\
\hline & 2Toyota & 0.2002 & 0.0702 & $\begin{array}{c}9 \\
0.742\end{array}$ & $\begin{array}{c}7 \\
0.545\end{array}$ & 0.2109 & 0 & 1 & 0 \\
\hline & 3Honda & 0.4555 & 0.2227 & 9 & 5 & 0.0841 & 0 & 0 & 1 \\
\hline
\end{tabular}

For this three-level hierarchy the priorities of the intermediate criteria nodes are zero at the second power. To display the priorities of all the nodes in the Goal column sum the first and second powers of the matrix. For an $n$-level hierarchy sum all the powers to display the priorities of all the nodes. As a matter of fact, the priorities in the Goal column are the eigenvector of the supermatrix. An interesting fact is that the eigenvector can be used to solve both the pairwise comparison matrix and to synthesize the priorities of the alternatives from the supermatrix. 
The synthesized priorities for the alternatives, in the Goal column of the limit supermatrix in Table 2Table 1 above, show that the Honda is the preferred choice with $45.5 \%$ of the priority while the Acura is second with $34.4 \%$ of the priority. Recall that Price in Table 1 had the highest priority of $42.5 \%$, and as the Honda had $74.3 \%$ of the priority for Price, this would be the outcome we would expect.

To gather and summarize the priorities of all the nodes in the model into a single matrix, sum the two states of the supermatrix from Table 1 and Table 2 and normalize the columns to 1 . The global or overall priorities of the nodes are given in the Goal column as shown in Table 3.

Table 3 Hierarchical Solution: Global Overall Priorities in Goal Column

\begin{tabular}{|c|c|c|c|c|c|c|c|c|c|}
\hline & & \multicolumn{2}{|c|}{$1 \mathrm{Goal}$} & \multicolumn{3}{|c|}{2 Criteria } & \multicolumn{3}{|c|}{ 3Alternatives } \\
\hline & & $\begin{array}{l}\text { Goal } \\
\text { Node }\end{array}$ & $\begin{array}{l}\text { 1Prestig } \\
\mathrm{e}\end{array}$ & 2Price & $3 \mathrm{MPG}$ & 4Comfort & $\begin{array}{l}\text { 1Acur } \\
\mathrm{a}\end{array}$ & $\begin{array}{l}\text { 2Toyot } \\
\mathrm{a}\end{array}$ & $\begin{array}{l}\text { 3Hond } \\
\text { a }\end{array}$ \\
\hline \multirow{3}{*}{$\begin{array}{l}\text { 1Goal } \\
\text { 2Criteria }\end{array}$} & $\begin{array}{l}\text { Goal } \\
\text { Node }\end{array}$ & 0 & 0 & 0 & 0 & 0 & 0 & 0 & 0 \\
\hline & 1Prestige & 0.0493 & 0 & 0 & 0 & 0 & 0 & 0 & 0 \\
\hline & 2Price & 0.2125 & 0 & 0 & 0 & 0 & 0 & 0 & 0 \\
\hline \multirow{5}{*}{$\begin{array}{l}\text { 3Altern- } \\
\text { atives }\end{array}$} & $3 \mathrm{MPG}$ & 0.0843 & 0 & 0 & 0 & 0 & 0 & 0 & 0 \\
\hline & 4Comfort & 0.1539 & 0 & 0 & 0 & 0 & 0 & 0 & 0 \\
\hline & 1Acura & 0.1721 & 0.7071 & 0.0633 & 0.1818 & 0.7049 & 1 & 0 & 0 \\
\hline & 2Toyota & 0.1001 & 0.0702 & 0.1939 & 0.2727 & 0.2109 & 0 & 1 & 0 \\
\hline & 3Honda & 0.2278 & 0.2227 & 0.7429 & 0.5455 & 0.0841 & 0 & 0 & 1 \\
\hline
\end{tabular}

To show the final priorities of the nodes by cluster, normalize the cluster priorities to one from the overall global priorities in the Goal column in Table 3. The cluster priorities and the global priorities are shown in Table 4. The final results for the alternatives are the cluster priorities.From the cluster priorities in Table 4 we see that the Honda, the least expensive car, has a high priority, 0.472, and we expected that because it had such a high priority with respect to Price, 0.743 .

Table 4 Hierarchical Model Final Priorities: Global and Normalized by Cluster

\begin{tabular}{|c|c|c|c|c|}
\hline & Clusters & Nodes & $\begin{array}{l}\text { Global Priorities } \\
\text { Cluster Priorities } \\
\end{array}$ & Normalized \\
\hline & 1Goal & Goal Node & 0 & 0 \\
\hline \multirow{4}{*}{\multicolumn{2}{|c|}{ 2Criteria }} & 1Prestige & 0.04935 & 0.09869 \\
\hline & & 2Price & 0.21249 & 0.42497 \\
\hline & & $3 \mathrm{MPG}$ & 0.08429 & 0.16857 \\
\hline & & 4Comfort & 0.15388 & 0.30777 \\
\hline \multirow{3}{*}{\multicolumn{2}{|c|}{ 3Alternatives }} & 1Acura & 0.17213 & 0.34427 \\
\hline & & 2Toyota & 0.10010 & 0.20021 \\
\hline & & 3Honda & 0.22776 & 0.45552 \\
\hline
\end{tabular}




\section{The ANP Model with Feedback}

To convert the previous hierarchical model to an ANP model with feedback from the alternatives to the criteria, first remove the goal, and then link the alternatives to the criteria, so the criteria will be judged in terms of how they present in the alternatives. The judgments about the cars with respect to the criteria are the same as in the hierarchical model. so you need only pairwise compare the criteria with respect to the cars to finish all the comparisons.

In AHP models the columns are always stochastic, but In ANP models the supermatrix may have columns that are not stochastic because there may be more than one priority vector in a column. In this case the columns must be weighted to make the entire column stochastic. This is done by first determining priorities for the clusters, then weighting the rows of the nodes in a cluster by its priority.

\section{Network Model with Feedback

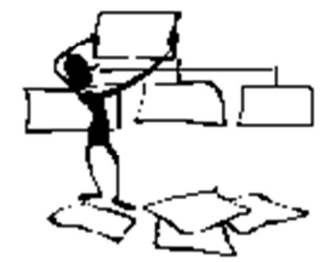

CRITERIA

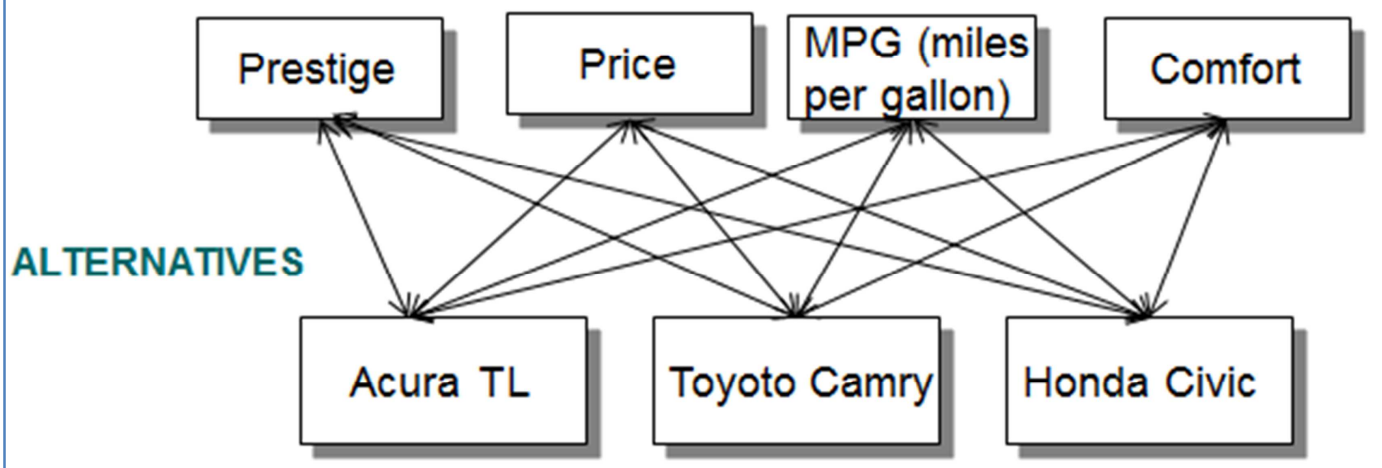

\section{Figure 3 ANP Model with Feedback}

Removing the goal causes the priorities of the criteria go back to their starting priorities that are equal by default, and their priorities have to be determined anew by comparing the criteria for their importance for each of the cars. 
This is a new kind of comparison question than the top-down sort normally used in hierarchical decision making. We give an example in Table 5 for the Acura. To show the thinking involved in comparing the criteria with respect to the cars, consider evaluating the criteria for the Acura. The pairwise comparison question may be phrased like this: "What do we like better about the Acura, its prestige or its price? Its prestige or its MPG? " Most decision makers would like prestige better and the judgments are entered into the matrix shown in Table 5:

The derived priority vector is sometimes referred to as the profile of the alternative in terms of the criteria. The priorities derived for the criteria shown in Table 5 represent the profile of the Acura. This is done for each of the cars and the three priority vectors are entered in Table 6.

Judging by these priorities, the Acura is valued for its prestige and its comfort. Price and MPG are not what the customer thinks important in evaluating the Acura.

Table 5 Example of Prioritizing the Criteria for an Alternative in the Feedback Model

\begin{tabular}{|c|c|c|c|c|c|}
\hline Acura & 1Prestige & 2Price & 3MPG & 4Comfort & $\begin{array}{c}\text { Priorities } \\
\text { Normalized } \\
\text { to One }\end{array}$ \\
\hline 1Prestige & 1 & 5 & 7 & 2 & 0.499 \\
\hline 2Price & $1 / 5$ & 1 & $1 / 2$ & $1 / 5$ & 0.066 \\
\hline $3 \mathrm{MPG}$ & $1 / 7$ & 2 & 1 & $1 / 7$ & 0.079 \\
\hline \multirow[t]{7}{*}{ 4Comfort } & $1 / 2$ & 5 & 7 & 1 & 0.355 \\
\hline & & & & & Inconsistency 0.073 \\
\hline & & \multicolumn{3}{|c|}{ Inconsistency: 0.07343} & \\
\hline & & 1Prestige & & \begin{tabular}{|l|l|}
0.49941 \\
\end{tabular} & \\
\hline & & 2Price & & 0.06591 & \\
\hline & & $3 \mathrm{MPG}$ & & 0.07944 & \\
\hline & & 4Comfort & & 0.35524 & \\
\hline
\end{tabular}

Figure 4 Profile of the Acura

This supermatrix shown in Table 6 is stochastic, and as the structure is no longer a hierarchy there is no need to insert the identity matrix for the alternatives as the matrix will converge without it.

Table 6 Supermatrix of the Feedback Model

\begin{tabular}{|c|c|c|c|c|c|c|c|c|c|}
\hline \multirow[t]{3}{*}{ Clusters } & & \multicolumn{5}{|c|}{ 2Criteria } & \multicolumn{3}{|c|}{ 3Alternatives } \\
\hline & & \multicolumn{2}{|l|}{ 1Prestig } & \multirow[b]{2}{*}{ 3MPG } & \multicolumn{2}{|r|}{ 4Comfor } & & \multirow[b]{2}{*}{ 2Toyota } & \multirow[b]{2}{*}{ 3Honda } \\
\hline & & e & 2Price & & & $\mathrm{t}$ & 1Acura & & \\
\hline \multirow{6}{*}{2 Criteria } & & & & & & & 0.49940 & 0.27531 & 0.06631 \\
\hline & 1Prestige & 0 & & & 0 & 0 & 7 & 9 & 5 \\
\hline & & & & & & & & 0.14855 & 0.56614 \\
\hline & 2Price & 0 & & & 0 & 0 & 0.06591 & 8 & 2 \\
\hline & & & & & & & 0.07944 & 0.12396 & 0.24736 \\
\hline & $3 \mathrm{MPG}$ & 0 & & & 0 & 0 & 5 & 7 & 6 \\
\hline
\end{tabular}




\begin{tabular}{llrrrrrrr} 
& 4Comfor & & & & & 0.35523 & 0.45215 & 0.12017 \\
& $\mathrm{t}$ & 0 & 0 & 0 & 0 & 8 & 6 & 7 \\
3Alternative & & 0.68172 & 0.06324 & 0.18182 & 0.70493 & & & \\
$\mathrm{~S}$ & 1 Acura & 5 & 8 & 1 & 6 & 0 & 0 & 0 \\
& & 0.23634 & 0.19387 & 0.27272 & & & & \\
& 2Toyota & 1 & 7 & 3 & 0.21092 & 0 & 0 & 0 \\
& & 0.08193 & 0.74287 & 0.54545 & 0.08414 & & & \\
& 3Honda & 5 & 5 & 5 & 4 & 0 & 0 & 0 \\
\hline
\end{tabular}

Raising the matrix in Table 6 to powers gives the steady state, or the limit supermatrix, shown in Table 7 . All the columns are the same and the column vector gives the global priorities of all the nodes in the model. Normalizing the priorities to one for each cluster of nodes gives the local cluster priorities and both the global and local cluster priorities are shown in

Table 8. The cluster priorities for the alternatives are the final overall priorities for the cars that are the objective of the decision model.

Table 7 Limit Supermatrix for the Feedback Model

\begin{tabular}{ll|rrrrrrrr}
\hline \hline & \multicolumn{1}{c}{ 2Criteria } & \multicolumn{3}{c}{ 3Alternatives } \\
\hline \hline \multirow{2}{*}{ 2Criteria } & & & \multicolumn{3}{c}{ 4Comfor } & 1Acura & 2Toyota & 3Honda \\
& & 1Prestige & 0.1588 & 0.1588 & 0.1588 & 0.1588 & 0.1588 & 0.1588 & 0.1588 \\
& 2Price & 0.1182 & 0.1182 & 0.1182 & 0.1182 & 0.1182 & 0.1182 & 0.1182 \\
& 3MPG & 0.0702 & 0.0702 & 0.0702 & 0.0702 & 0.0702 & 0.0702 & 0.0702 \\
& 4Comfort & 0.1527 & 0.1527 & 0.1527 & 0.1527 & 0.1527 & 0.1527 & 0.1527 \\
3Alternative & & & & & & & & \\
s & 1Acura & 0.2362 & 0.2362 & 0.2362 & 0.2362 & 0.2362 & 0.2362 & 0.2362 \\
& 2Toyota & 0.1118 & 0.1118 & 0.1118 & 0.1118 & 0.1118 & 0.1118 & 0.1118 \\
& 3Honda & 0.1520 & 0.1520 & 0.1520 & 0.1520 & 0.1520 & 0.1520 & 0.1520 \\
\hline
\end{tabular}

Table 8 Global Priorities and Priorities Normalized by Cluster for the Feedback Model

Local

Clusters Nodes $\quad$ Global Priorities

\begin{tabular}{|c|c|c|c|c|}
\hline & 1Goal & 0 & 0 & 0 \\
\hline & 2Criteria & 1Prestige & 0.1588 & 0.3176 \\
\hline & & 2Price & 0.1182 & 0.2365 \\
\hline & & $3 \mathrm{MPG}$ & 0.0702 & 0.1405 \\
\hline & & 4Comfort & 0.1527 & 0.3055 \\
\hline \multirow[t]{3}{*}{ 3Alternatives } & & 1Acura & 0.2362 & 0.4724 \\
\hline & & 2Toyota & 0.1118 & 0.2236 \\
\hline & & 3Honda & 0.1520 & 0.3040 \\
\hline
\end{tabular}


The global priority of the Acura has increased from 0.172 in the hierarchical model to 0.236 (see Table 3) until it is now the preferred car in the ANP model with feedback (see

Table 8), while the global priority of Price has decreased from 0.212 in the hierarchical model to 0.118 . The revisions in priority are due to integrating specific information about the actual cars being considered into the model; in other words, using feedback. Synthesizing priorities from the pairwise comparisons in an ANP model cannot be done by weighting and adding. It is necessary to use the supermatrix and raise it to powers to allow the interactions in the system to net out overall priorities.

\section{ANP Network with Feedback and Dependence}

We shall now add dependence links among the criteria as shown in Figure 5. We will link Price to Prestige and Comfort, meaning that price depends on the prestige and comfort it can bring. The pairwise comparison question is: "Which influences Price more, the Prestige of a car or its Comfort?" Most people tend to think it is Prestige and a judgment of 5 was used here, resulting in the priorities of 0.833 for Price and 0.167 for Comfort. We shall also link Prestige to Price and Comfort. The question this time is: "Which influences Prestige more, Price or Comfort?" Again, most people equate prestige with price, so price drives the priority of prestige more than comfort does, so a judgment of 3 was used here, resulting in priorities of 0.75 for Prestige and 0.25 for Comfort. These values are entered in the appropriate columns in the supermatrix for the ANP model with feedback and dependence shown in Table 9. All the other priorities derived from pairwise comparing remain the same as they were before the inner dependent links were added.

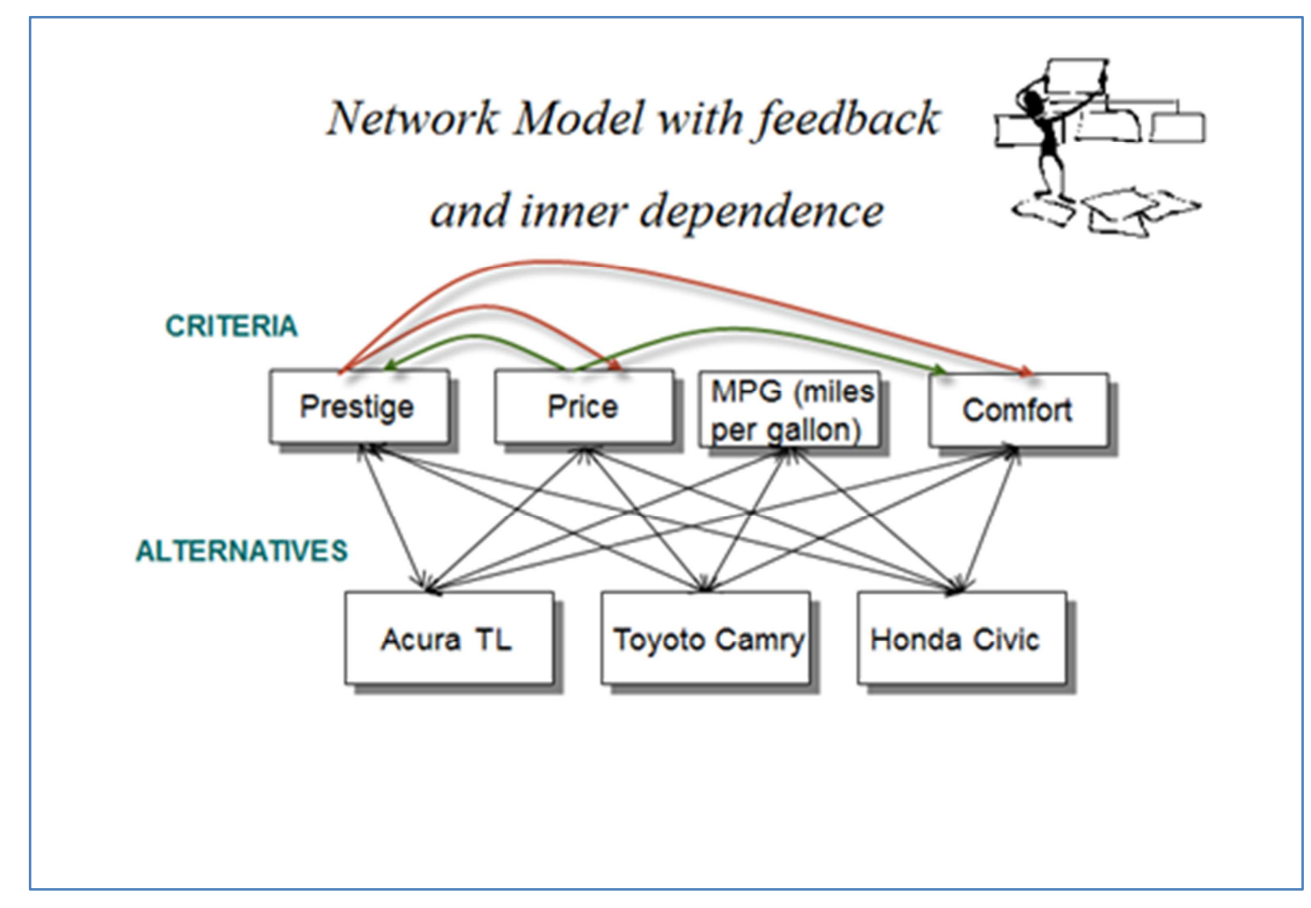

Figure 5 Network Model with Feedback plus Inner Dependence 
The unweighted supermatrix is shown in Table 9. We have added the term "unweighted" because the supermatrix is no longer stochastic. Some of the columns now sum to 2 because there are two priority vectors in some columns, stacked one on top of the other, and the sum is 2 in that case.

We can make the columns in Table 9 stochastic, by prioritizing the clusters and weighting blocks of numbers by these priorities. For more detail about how weighting the clusters is used to convert an unweighted supermatrix into a stochastic matrix refer to Saaty's book on mathematical principles of decision making (Saaty, 2010). For the purposes of this paper, we shall merely assume the Criteria and Alternatives clusters have equal weights of .5 and multiply the respective blocks of numbers in Table 9 by 0.5 to obtain Table 10 in which the columns sum to 1 to give the weighted supermatrix.

Table 9 Unweighted Supermatrix for the ANP Model with Feedback and Dependence

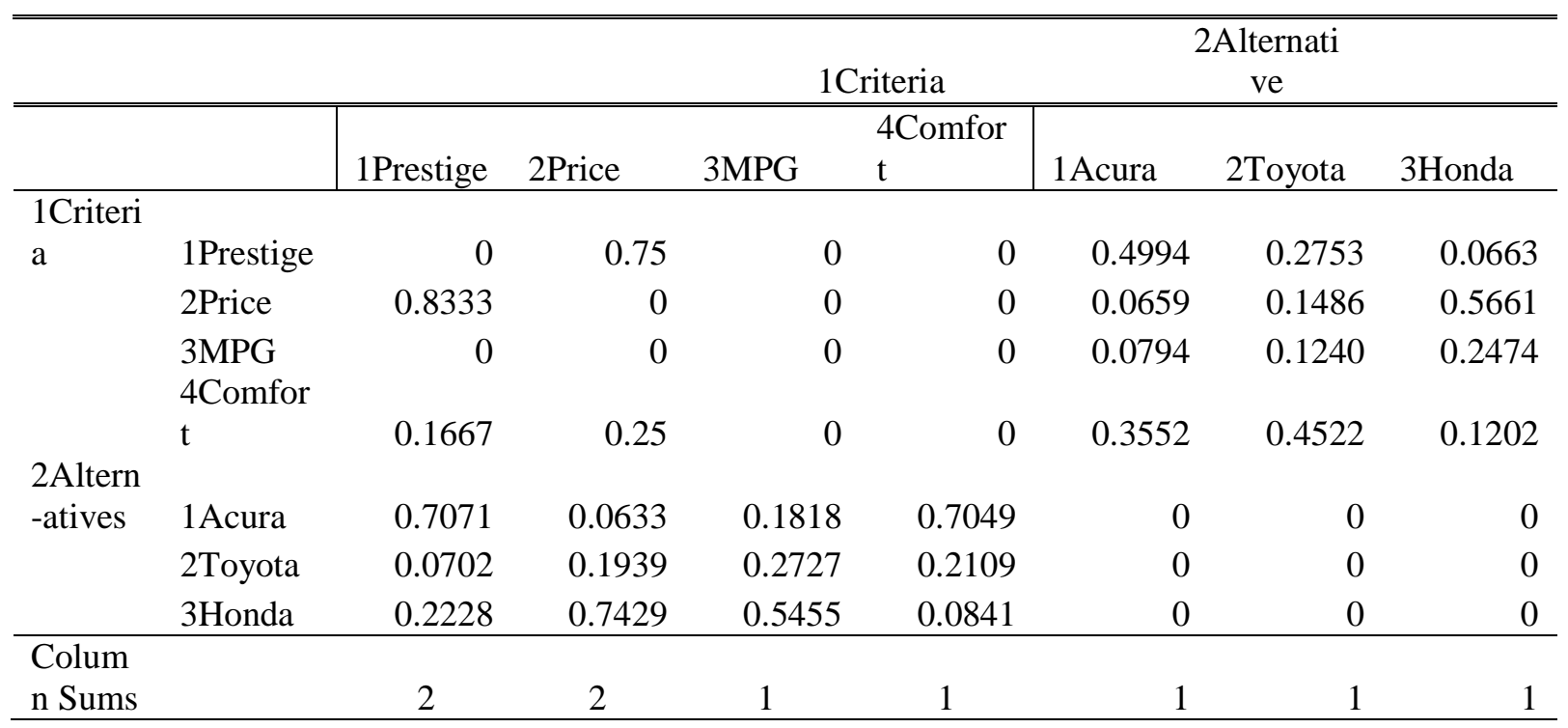

Table 10 Weighted Supermatrix for the ANP Model with Feedback and Dependence

\begin{tabular}{|c|c|c|c|c|c|c|c|c|}
\hline & & \multicolumn{4}{|c|}{2 Criteria } & \multicolumn{3}{|c|}{ 3Alternatives } \\
\hline & & 1Prestige & 2Price & $3 \mathrm{MPG}$ & $\begin{array}{l}\text { 4Comfor } \\
\mathrm{t}\end{array}$ & 1Acura & 2Toyota & 3Honda \\
\hline \multirow[t]{4}{*}{2 Criteria } & 1Prestige & 0 & 0.3750 & 0 & 0 & 0.4994 & 0.2753 & 0.0663 \\
\hline & 2Price & 0.4167 & 0 & 0 & 0 & 0.0659 & 0.1486 & 0.5661 \\
\hline & $3 \mathrm{MPG}$ & 0 & 0 & 0 & 0 & 0.0794 & 0.1240 & 0.2474 \\
\hline & 4Comfort & 0.0833 & 0.1250 & 0 & 0 & 0.3552 & 0.4522 & 0.1202 \\
\hline \multicolumn{9}{|l|}{ 3Alternative } \\
\hline \multirow[t]{3}{*}{$\mathrm{s}$} & 1Acura & 0.3536 & 0.0316 & 0.1818 & 0.7049 & 0 & 0 & 0 \\
\hline & 2Toyota & 0.0351 & 0.0969 & 0.2727 & 0.2109 & 0 & 0 & 0 \\
\hline & 3Honda & 0.1114 & 0.3714 & 0.5455 & 0.0841 & 0 & 0 & 0 \\
\hline \multicolumn{9}{|l|}{ Column } \\
\hline Sums & & 1 & 1 & 1 & 1 & 1 & 1 & 1 \\
\hline
\end{tabular}


The next step is to raise the weighted supermatrix to powers until it converges to the limit supermatrix shown in Table 11. The weighted supermatrix for a simple feedback model is well-behaved and converges quickly to a limit matrix with all the columns the same.

Table 11 Limit Supermatrix for the ANP Model with Feedback and Dependence

\begin{tabular}{|c|c|c|c|c|c|c|c|c|}
\hline & & \multicolumn{4}{|c|}{ 2Criteria } & \multicolumn{3}{|c|}{ 3Alternatives } \\
\hline & & 1Prestige & 2Price & $3 \mathrm{MPG}$ & $\begin{array}{l}\text { 4Comfor } \\
\mathrm{t}\end{array}$ & 1Acura & 2Toyota & 3Honda \\
\hline \multirow[t]{4}{*}{2 Criteria } & 1Prestige & 0.1960 & 0.1960 & 0.1960 & 0.1960 & 0.1960 & 0.1960 & 0.1960 \\
\hline & 2Price & 0.1817 & 0.1817 & 0.1817 & 0.1817 & 0.1817 & 0.1817 & 0.1817 \\
\hline & $3 \mathrm{MPG}$ & 0.0581 & 0.0581 & 0.0581 & 0.0581 & 0.0581 & 0.0581 & 0.0581 \\
\hline & 4Comfort & 0.1587 & 0.1587 & 0.1587 & 0.1587 & 0.1587 & 0.1587 & 0.1587 \\
\hline \multicolumn{9}{|l|}{ 3Alternative } \\
\hline \multirow[t]{3}{*}{ s } & 1Acura & 0.1975 & 0.1975 & 0.1975 & 0.1975 & 0.1975 & 0.1975 & 0.1975 \\
\hline & 2Toyota & 0.0738 & 0.0738 & 0.0738 & 0.0738 & 0.0738 & 0.0738 & 0.0738 \\
\hline & 3Honda & 0.1343 & 0.1343 & 0.1343 & 0.1343 & 0.1343 & 0.1343 & 0.1343 \\
\hline
\end{tabular}

The final step is to present the column as the global priorities, and normalize the cluster priorities to one, as shown in Table 12.

Table 12 Global Priorities and Normalized Cluster Priorities for Feedback and Dependence Model

\begin{tabular}{llcc}
\hline \hline Clusters & Nodes & Global Priorities & Local Cluster Priorities \\
\hline 1Goal & 0 & 0 & 0 \\
2Criteria & 1Prestige & 0.1960 & 0.3297 \\
& 2Price & 0.1817 & 0.3056 \\
& 3MPG & 0.0581 & 0.0977 \\
3Alternatives & 4Comfort & 0.1587 & 0.2670 \\
& 1Acura & 0.1975 & 0.4869 \\
& 2Toyota & 0.0738 & 0.1819 \\
& 3Honda & 0.1343 & 0.3312 \\
\hline
\end{tabular}

\section{Summary}

To summarize the results we first show how the priorities of the criteria change as more information is incorporated into the decision model as shown in Table 13. In the hierarchical model the Price criterion is given greater importance than it likely deserves. Hierarchical models evaluated top-down from the Goal are using judgments not based on examining the actual alternatives, but on abstract considerations in the mind of the decision maker. This tends not to give results that match what happens in real life. There is an informal way to incorporate more information about the alternatives in AHP models by first evaluating the alternatives in terms of the criteria, then evaluating the importance of the criteria. But in an ANP model this is much more explicit.

Table 13 Change in Criterion Priorities as Model incorporates more Information 


\begin{tabular}{lccc}
\hline Criteria & $\begin{array}{c}\text { AHP Hierarchical } \\
\text { Model }\end{array}$ & ANP Feedback Model & $\begin{array}{c}\text { ANP Dependence and } \\
\text { Feedback Model }\end{array}$ \\
\hline Prestige & 0.099 & 0.318 & 0.330 \\
Price & 0.425 & 0.236 & 0.306 \\
Miles per Gallon (MPG) & 0.169 & 0.140 & 0.098 \\
Comfort & 0.308 & 0.305 & 0.267 \\
\hline
\end{tabular}

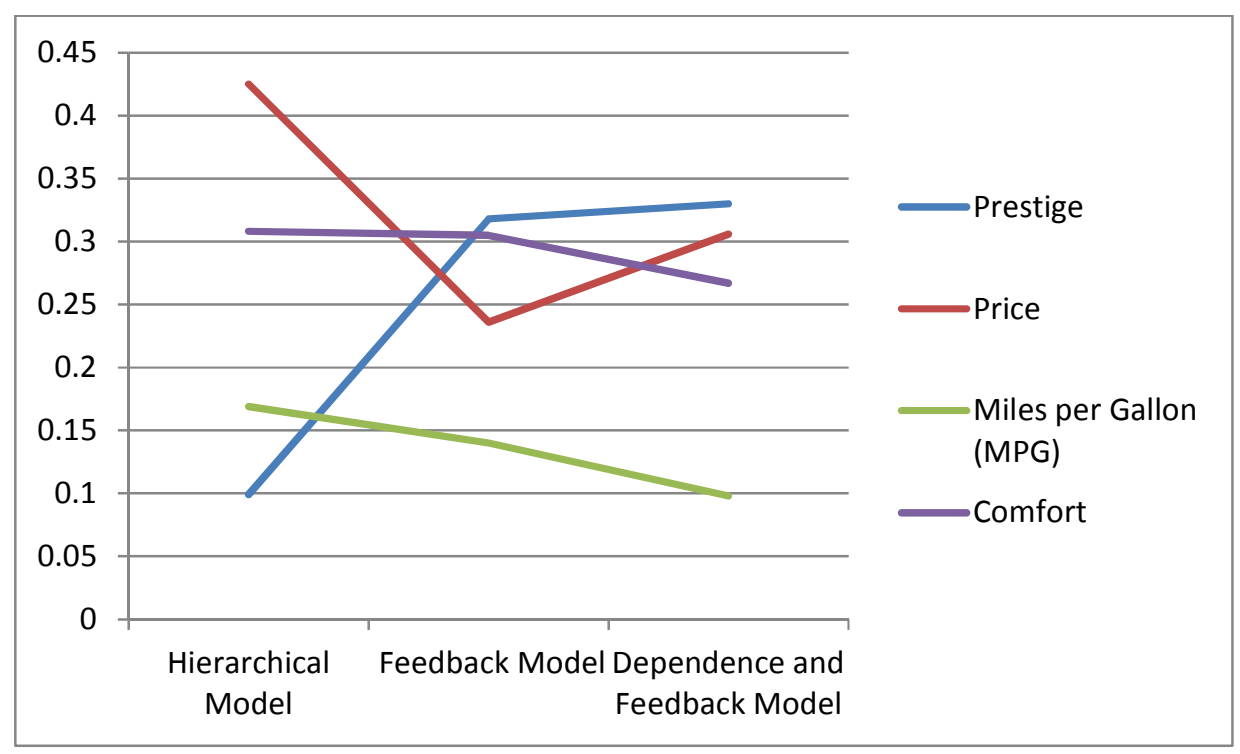

Figure 6 Change in Priorities of Criteria as Model Complexity increases

Due to the overwhelming priority of Price in the hierarchical model as shown in Figure 6 the Honda Civic was the best choice as shown in Figure 7. In the feedback model, after considering the actual alternatives, Price dropped considerably in importance and the Acura because the best choice. Finally inner dependence among the criteria was added to the model and the Acura became an even somewhat better choice than before.

Table 14 Summary of Results of for Alternatives

\begin{tabular}{lccc}
\hline Alternatives & $\begin{array}{c}\text { AHP Hierarchical } \\
\text { Model }\end{array}$ & ANP Feedback Model & $\begin{array}{c}\text { ANP Dependence and } \\
\text { Feedback Model }\end{array}$ \\
\hline Acura TL & 0.344 & 0.472 & 0.487 \\
Toyota Camry & 0.200 & 0.224 & 0.182 \\
Honda Civic & 0.455 & 0.304 & 0.331 \\
\hline
\end{tabular}




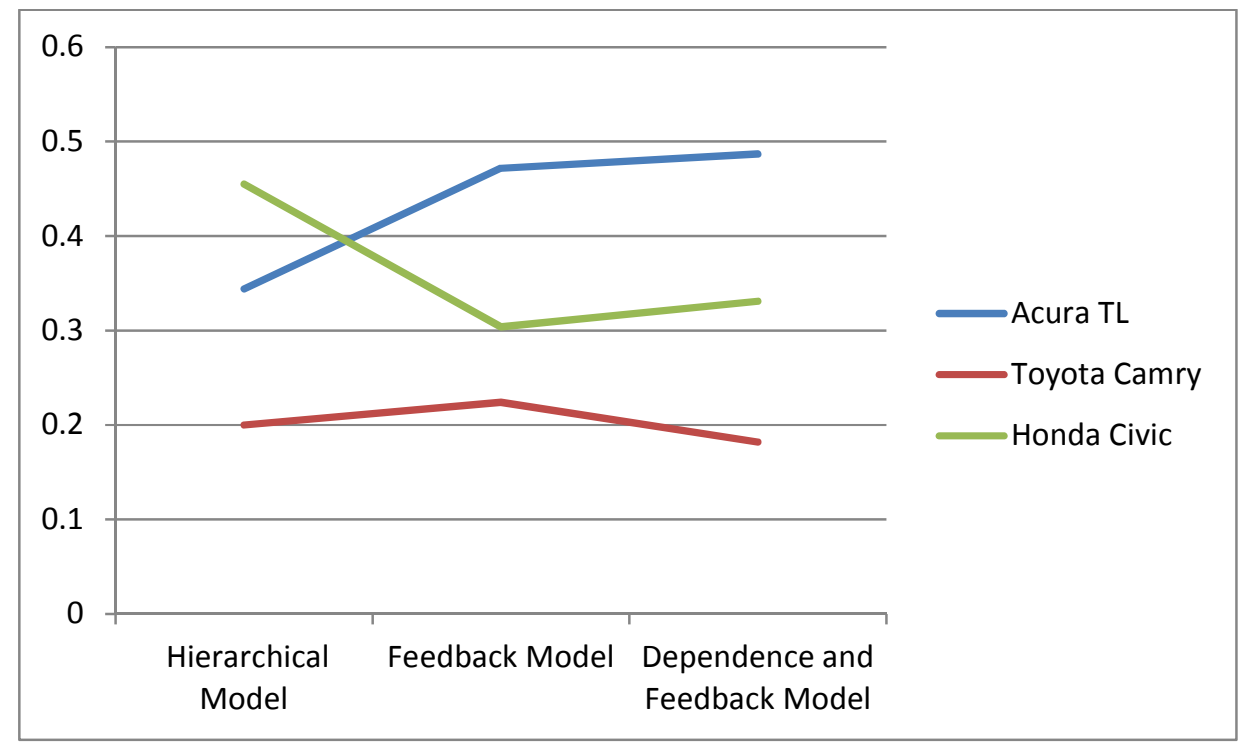

Figure 7 Change in Priorities of Cars as Model more closely captures Real World

In conclusion, all decisions are "good" only as they satisfy the decision maker. Our satisfaction is the ultimate goal of any decision we make. In this decision we have posited a hypothetical situation and hypothetical decision-maker that nonetheless most of us can identify with. The ANP is a robust decision making theory. If you ask the pairwise questions in the right way and put in good judgments the ANP process will net out good results that can be validated against real world outcomes. As a validation here we offer the evidence that expensive cars do sell.

\section{REFERENCES}

Adams, William J. and Saaty, Rozann W. 2013. SuperDecisions Software. Pittsburgh : Creative Decisions Foundation, 2013.

Saaty, Thomas L. 2010. Principia Mathematica: Principles of Decision Making. Pittsburgh : RWS Publications, 2010. ISBN 978-1-888603-10-1.

- 2013. Theory and Applications of the Analytic Network Process: Decision Making with Benefits, Opportunities, Costs and Risks. Pittsburgh : RWS Publications, 2013. ISBN 978-1-8886031-6-3; ebook. 